\title{
The Ageing Society and Emergency Hospital Admissions
}

Raphael Wittenberg $\square$ Raphael.wittenberg@phc.ox.ac.uk

Luke Sharpin

Barry McCormick

Jeremy Hurst

Centre for Health Service Economics and

Organisation, Nuffield Department of Primary Care

Health Sciences, Radcliffe Observatory Quarter,

Woodstock Road, 0xford 0X2 6GG, United Kingdom

$\square$ Corresponding author.

\section{Abstract}

There is strong policy interest, in England as elsewhere, in slowing the growth in emergency hospital admissions, which for older people increased by $3.3 \%$ annually between $2001 / 2$ and 2012/3. Resource constrains have increased the importance of understanding rising emergency admissions, which in policy discourse is often explained by population aging. This study examines how far the rise in emergency admissions of people over 65 was due to population ageing, how far to the changing likelihood of entering hospital at each age, and how far to other factors which might be more amenable to policy measures. 
It shows that: admission rates rose with age from age 40 upward but each successive birth cohort experienced lower emergency admission rates after standardising for age and other effects. This downward cohort effect largely offset the consequences of an older and larger population aged over 65 . other factors which could explain increasing admissions, such as new technologies or rising expectations, appear more important than the changing size and age structure of the population as drivers of rising emergency admissions in old age. These findings suggest that stemming the rate of increase in emergency admissions of older people may be feasible, if challenging, despite population ageing. (200 words)

Keywords

Emergency admissions; older people; ageing; cohort effect 


\section{The Ageing Society and Emergency Hospital Admissions}

\section{Introduction Section}

Emergency inpatient care of older people is an issue of considerable policy concern in England as in other countries. For example, recent Department of Health policy goals include "a measurable reduction in age standardised emergency admission rates and emergency inpatient bed-day rates" by 2020 [1], while the Department of Health 2016 Shared Delivery Plan [2] comments that "Improved care in out-of-hospital settings is expected to lead to reduced need for emergency admissions to hospital, and to shorter stays for those who are admitted, and hence a fall in the number of emergency bed days per head of population".

Inpatient hospital care can be highly effective; but it is also very costly and may not be in the interests of patients' quality of life if treatment elsewhere is feasible. Despite the concerns of policy makers, the numbers of emergency hospital admissions in England have been rising for at least the last 25 years, at times rapidly and at times more slowly. The National Beds Inquiry [3] reported that emergency admissions per head increased by 2.1\% per year between 1989 and 1998 for the whole population and by 3.0\% per year for the older population (age 65 and over). The Nuffield Trust [4] found that emergency admissions among the overall population 
rose by $2.8 \%$ per year between $1998 / 9$ and 2008/9, implying a rate of $2.3 \%$ per head per year.

Increases in emergency hospital admissions are not peculiar to England. In the USA the numbers of emergency admissions via emergency departments involving at least one overnight stay rose by 3.2\% per year between 1993 and 2006, which implies an average annual rise of some $2.2 \%$ in the rate per head [5].

The key question this article addresses is how far the rise in emergency admissions of older people (aged 65 and over) is due to population ageing and how far to other factors. This is very relevant for the future financing and planning of emergency care. If the rise is due mainly to population ageing, it will inevitably continue over the coming decades as the rise in numbers of older people accelerates. If it is due mainly to other factors, or if the impact of ageing is at least partially offset by other factors, there may be greater prospect of slowing the rise in emergency admissions.

The number of people aged 65 and over in England rose from 7.8 million in 2001 to 9.1 million in 2012, and is projected to reach 10.6 million in 2020 and 13.2 million in 2030 . These rises are due partly to increasing life expectancy and partly to the baby boom cohorts of 1945 to 1964 reaching old age in increasing numbers. Larger cohorts, other factors equal, mean higher costs, but other factors may not be equal: the upward 
pressure from rising numbers could be offset by factors such as better health among later cohorts or better care.

Past studies have found that less than half the increase in emergency admissions is due to the increase in numbers of older people $[6,7]$. Other drivers have been discussed in the literature, including changes in technology, medical practice, expectations, and policy incentives $[6,7,8,9]$. The latter, it has been suggested, could include an incentive to admit patients briefly arising from the payment by results system [9] or the 4 hour waiting time target for A\&E attendances [7].

Various initiatives have been pursued to stem this increase in emergency admissions. These include measures which are being pursued internationally, such as better care co-ordination, as well as measures which relate specifically to the health and social care system in England and its financing arrangements, such as reimbursing additional admissions above a set level at a reduced rate [10]. The importance of such initiatives has been sharpened by constraints on public expenditure on health care in England and elsewhere.

Urgent and emergency services have been the subject of a wide range of policy discourse and policy decisions in recent years, including the Urgent and Emergency Care Review [11]. This has been prompted by a belief that the system is currently facing severe stress, at least in winter. 
The House of Commons Health Committee conducted a study of urgent and emergency care and published a report in July 2013 [12]. They noted that 'whilst growth in attendances at emergency departments has been limited, admissions have grown substantially placing more pressures on hospitals and restricting the ability of emergency departments to manage the flow of patients'.

The English National Health Service (NHS) is funded mainly from general taxation and is almost entirely free at point of use. Decisions on the level of spending on the NHS are largely at the discretion of the government of the day. Since the middle of the last decade, providers have been paid for secondary health care, including inpatient stays, through a national 'payment by results' (PbR) system which is a form of prospective, fixed price, case based payment system. Payments are linked to activity and adjusted case-mix.

This article focuses on the question of how far the rise in emergency admissions of older people over the period 2001/02 to $2012 / 13$ was due to the rise in the numbers of older people and how far to other factors such as trends in health status among successive cohorts, advances in technology or policy changes. It extends the scope of earlier studies through: a focus on older people; inclusion of more recent trends; and an analysis of age, cohort and period effects to examine the 
increase in admissions of older people. Section 2 presents the data and methods, section 3 sets out our key findings, section 4 discusses the findings and section 5 concludes.

\section{Data and methods}

Our study comprised analyses of Hospital Episode Statistics (HES) inpatient data for England together with office for National Statistics population estimates [13] HES contain details of all admissions, outpatient appointments and accident and emergency (A\&E) attendances at NHS hospitals in England [14]. The data is collected during a patient's time at hospital and is submitted to allow hospitals to be paid under the case-based system for the care they deliver.

HES include a range of data for each hospital episode and a facility to link episodes into spells, where a spell is the period from admission to death or discharge. Our analyses use data on the patient's age, type of admission (emergency or elective), diagnoses, procedure, duration of spell and financial year of admission. We used descriptive statistics to present trends in emergency admissions by age band, health condition and procedure. Further details are presented in Wittenberg et al. [15]

We used a regression-based methodology to partition past trends in emergency admissions between age, period and cohort (APC) effects. The APC method, which is discussed in Yang and 
Land [16], is a valuable way to examine factors underlying time trends. APC analyses have been conducted in studies of trends in mortality rates and in prevalence rates of diseases. They have rarely, if ever, to our knowledge been used to examine trends in hospital admissions in England.

APC analysis is a form of multivariate regression analysis. The dependent variable is counts by age and year of the variable to be analysed or, as in our analysis, those counts by age and year expressed as rates e.g. per 1,000 population. The independent variables are dummy variables for each age, year of birth and year of admission. The model specification is as follows:

$$
M_{i j}=D_{i j} / P_{i j}=\mu+\alpha_{i}+\beta_{j}+\gamma_{k}+\varepsilon_{i j}
$$

- Mij denotes the observed occurrence/exposure rate of admissions for the $i$-th age group for $i=1, \ldots, a$ age groups at the $j$-th time period for $j=1, \ldots, p$ time periods of observed data

- $D_{i j}$ denotes the number of admissions in the $i j$-th group, $P_{i j}$ denotes the size of the estimated population in the $i j-t h$ group

- $\mu$ denotes the intercept or adjusted mean

- $\alpha_{i}$ denotes the $i-t h$ row age effect or the coefficient for the $i$-th age group

- $\beta_{j}$ denotes the $j$-th column period effect or the coefficient for the $j$-th time period 
- $r k$ denotes the $k$-th cohort effect or the coefficient for the $k$-th cohort for $k=1, \ldots,(a+p-1)$ cohorts, with $k=a-i+j$

- $\varepsilon_{i j}$ denotes the random errors with expectation $E\left(\varepsilon_{i j}\right)$ $=\odot$

A problem arises however when attempting to apply the APC method econometrically, in that age, period and cohort are perfectly multi-collinear: period = age and cohort, e.g. if a person was born in 1960 (cohort) and was aged 50 (age) this identifies the year as 2010 (period). One way to handle this multicollinearity issue is to impose a restriction on the regression parameters. We have however adopted the Intrinsic Estimator (IE) approach, which avoids the need to impose potentially arbitrary constraints on the regression parameters. It instead restricts the impact of the design matrix (the data entered in the model) on the coefficient estimates. In practice, this implies that the constraint is determined by the number of age and period groups modelled [17]. The method is discussed in more detail in a technical annex which also includes charts showing the regression coefficients.

We calculated separate rates of emergency admission for each single year of age for each year of admission from 2001/02 to 2012/13. The dependent variable comprises these rates with a separate observation for each combination of year of age and 
year of admission. We included three independent variables: patients' age, year of birth and year of emergency admission. We used Stata version 12.

We ran two versions of the APC regression, for people of all ages and for older people only. The reason is to check that the age effect turns upward from a much younger age than 65 and that the period and cohort effects do not differ substantially between older people and the whole population. We present here the results of the regression for older people.

Age effects relate to differences in emergency admission rates by age after controlling for any differences in the other two factors. They are ascertained by examining admission rates at each age averaged across each birth cohort and each time period. The age effect is likely to reflect the way in which the underlying need for emergency inpatient care varies by age, after allowing for cohort and period effects.

Cohort effects relate to differences in emergency admission rates by birth cohort after controlling for any differences in the other two factors. They may be seen as generational differences. They are ascertained by examining the admission rates of each cohort at each age averaged across each time period. The cohort effect is therefore likely to reflect the way in which the underlying need for emergency inpatient care 
varies by birth cohort, after allowing for age and period effects, possibly in turn reflecting changes over time in the incidence of conditions requiring urgent and emergency care.

Period effects relate to residual differences over time in emergency admission rates after controlling for any differences in the other two factors. They are ascertained by examining for each time period the admission rates of each cohort at each age. The period effect is therefore generally likely to reflect not underlying need for emergency inpatient care but other contemporaneous factors. These could include changes in demand, such as changes in clinicians' views about the benefits of hospital admission for older patients. They could also include supply side factors, such as advances in technology or take-up of new technologies or changes in policy such as increased or reduced health care funding.

\section{Results}

$\underline{\text { Admissions }}$

The number of emergency admissions for people aged 65 and above in England have increased year on year since 2001/2. They continued to rise even after NHS expenditure was held constant in real terms from $2010 / 11$. They rose by $45.6 \%(3.5 \%$ per year) from 1.52 million admissions in 2001/12 to 2.21 million in 2012/13. 
Emergency admission rates of people aged 65 and over per thousand older population have increased by almost $26 \%$ (2.1\% per year) over the period 2001/02 to 2012/13 (or by 25\% on an age-standardised basis). While the rate rose by only $0.8 \%$ per year for the 65 to 69 age group, it rose by 3.8\% per year for the 90 and over age group.

The rise in emergency admissions, while greatest for older people, was not limited to the older population. Similar but less pronounced increases were observed for working age adults (aged 20 to 64) and younger people (aged $\odot$ to 19), with annual growths of $2.8 \%$ and $2.0 \%$ respectively in comparison with $3.5 \%$ for older people. Rates for people aged 65 to 79 actually increased more slowly than for people aged under 65 .

The rise relates mainly to admissions with short hospital stays. The number of short spells ( $\odot$ or 1 day) [18] rose far faster than the number of longer spells (2 or more days), 10.2\% per year in comparison with $1.7 \%$ per year.

The rise in numbers of admissions of older people was accompanied by an increase in the proportion of emergency admissions involving procedures including diagnostic procedures. The proportion of emergency admissions which involved a procedure rose from $27 \%$ in $2006 / 07$ to $33 \%$ in 2012/13. The numbers of emergency admissions rose between $2001 / 02$ and $2012 / 13$ for almost all the main International 
Classification of Disease (ICD) chapters, with the sole exception (among chapters with over 10,000 admissions) of neoplasms, where the numbers fell by $9 \%$. There were especially large rises for pneumonia and $\mathrm{flu}$ and for urinary tract infection, which are among the conditions for which admissions have been classed as potentially avoidable.

Bed days and lengths of stay

Despite the rise in emergency admissions, total number of emergency bed days for older people fell from 22.0 million in $2001 / 02$ to 20.0 million in $2012 / 13$, a decline of $9.1 \%$ over the eleven years or an average of $\odot .8 \%$ per year. It fell by $14.0 \%$ by $2007 / 08$ and then rose by $1.9 \%$ between then and $2012 / 13$. The age-standardised bed day rate per thousand older population fell by $25 \%$ over the eleven year period, an average of $2.0 \%$ per year. This fall facilitated the rise in emergency admissions by creating the necessary bed capacity to admit more patients.

The divergence between trends in emergency admissions and trends in bed days associated with these admissions comprises two factors. First, the number of short spells ( $\theta$ or 1 day) rose far faster than the number of longer spells (2 or more days), as explained above. Second, the mean length of stay of longer spells fell. Lengths of stay have fallen consistently during the period, by $2.0 \%$ per year or $25 \%$ in all, equivalent 
to 4 fewer days per hospital spell, with smaller proportionate declines for the younger old: a 1.6\% annual reduction for 65 to 69 year olds compared to a $2.3 \%$ annual reduction for those aged 90 and over.

\section{Age, period and cohort effects}

The age effect, estimated from the APC model, is as would be expected: admission rates rise monotonically with age from age 65 upward (or from age 40 upward in the APC analysis for all age groups). The emergency admission rate is almost $50 \%$ higher at age 75 and around 150\% higher at age 85 than at age 65, on the basis of constant 2010 period effect and 1935 cohort effect (Figure 1).

Figure 1 around here

The cohort effect is perhaps more surprising: each cohort from those born in around 1924 onward has, with few exceptions, experienced lower emergency admission rates after standardising for age and period effects. This downward cohort effect is large and offsets much of the upward age effect over the period $2001 / 02$ to $2012 / 13$. The emergency admission rate for those born in 1940 for example is around 20\% lower than the rate for those born in 1920, estimated for age 75 and constant 2010 period effect. The rate for those born in 1945 is likely to be $35 \%$ lower than for the 1920 cohort (Figure 2). Figure 2 around here 
Period effects have been increasing since 2001/02. They rose especially sharply between around 2002/03 and 2005/06 and have continued to rise despite resource constraints in the most recent years. The emergency admission rate in $2012 / 13$ is around $40 \%$ higher than the rate in 2001/02, estimated for the 1935 cohort and age 75 (Figure 3 ). This could, as discussed below, reflect a range of factors including changes in NHS funding and uptake of new technologies.

Figure 3 around here

Separate APC analyses for men and women found little difference by gender for the size of the cohort or period effects. For age effects, emergency admission rates rise with age from age 30 for men and from age 45 for women. Separate analyses for short duration ( $\odot$ or 1 day) and longer duration ( 2 or more days) emergency stays found little difference in age effects but substantial differences in cohort and period effects. While the cohort effect has been downward for both short and long duration stays since 1970, from 1930 to 1970 the cohort effect was upward for short duration stays but downward for long duration stays. The period effect was substantially greater for short than for long duration stays. Further details of these analyses are available in (Wittenberg et al. [19]. 


\section{$\underline{\text { Discussion }}$}

The numbers of emergency admissions among older people in England rose considerably faster than the older population in the eleven years between 2001/02 and 2012/13: admissions per older person rose on average by $2.1 \%$ per year over this period. The average duration of emergency inpatient spells of older patients, however, fell sharply. As a result, despite the rise in admissions, the number of emergency bed days per older person declined by about $2.0 \%$ per year. This is remarkable viewed from the perspective of a decade ago when the projected rapid rise in numbers of the older people suggested a likely rise in need for hospital capacity. The NHS has succeeded in providing more spells of emergency care for older people with fewer beds.

The age effect in the APC analysis is not surprising. The prevalence rates of serious illnesses such as ischaemic heart disease and stroke rise with age as does the prevalence of multi-morbidity.

The APC analysis finding of a downward cohort effect is of particular interest. It suggests that the underlying need by age for emergency inpatient care of older people has been falling for many years. This would be consistent with falling prevalence rates of some health conditions and with rising life expectancy and healthy life expectancy [20]. It could be 
due to the impact on health of rising living standards and to improved primary and community care.

The growing evidence on the association between health care costs and proximity to death seems pertinent. Various studies in different countries have shown that expenditure on acute health care rises with proximity to death rather than with age, that is it rises in line with time from the end rather than from the start of life $[21,22]$. This suggests that, as life expectancy rises, use of acute health care services in younger old age falls. Our APC analysis finding on the downward cohort effect is consistent with this.

The downward cohort effect offset much of the age effect and the impact of rising numbers of older people over the period 2001/02 to 2012/13. If emergency admission rates by age and gender had remained constant, that is constant cohort and period effects, there would have been around 1.76 million admissions in 2012/13, an increase of $16 \%$ in the number of emergency admissions of older people over the period (Table 1). The combined impact of this upward ageing effect and the downward cohort effect would, if there had been no period effect, have resulted in 1.60 million admissions in 2012/13, an increase of only $5.3 \%$, as estimated using the findings of the APC analysis. The rise in emergency admissions was almost entirely due to a period effect. 
Table 1 around here

While the age and cohort effects are likely to reflect demographic and epidemiological change, the period effects capture admissions that could not have been anticipated given evidence from previous years: these would reflect both supplyside and policy innovations as well as any specific pressures on patient demand at a specific time. One possible explanation, arguably the most important explanation, is the sharp rise in NHS resources during much of the 2000s. The UK Government decided in 2000 to raise the UK's share of health spending in GDP to the European average by 2006. NHS spending increased by more than $60 \%$ in real terms between 2001 and 2009 and then stabilised following the imposition of austerity on the NHS in 2010/11. Much of the spending went into hospital emergency services, at least early in the decade.

Arguably one of the reasons for the substantial increase in NHS expenditure following the NHS Plan was to improve access to new and existing technologies. There have over the last decade been improvements in access to relatively new diagnostics, drug therapies and surgical procedures, a rise in the numbers and types of imagining and radio-diagnostic examinations and a rise in the proportion of older emergency admissions involving a procedure [15]). Evidence for the important role of technology is that the numbers of spells 
involving procedures has risen much more rapidly than the number not involving procedures and that the number of short spells ( $\odot-1$ day) have risen far faster than the number of longer spells (2 or more days).

An important implication of our research is that, despite rising numbers of older people, underlying demand pressures may have been more limited, and may continue to be more limited, than would be expected from consideration of population projections alone. Nevertheless, unless the upward trend in period effects can be halted, which may prove challenging, the number of emergency admissions of older people will continue to rise, especially when the overall numbers of older people start to rise more rapidly in the 2020 s.

The implication of a combination of continuing upward pressure on resources for emergency inpatient care and continuing constraint on real terms growth in expenditure is that it will remain important for the NHS and its partners to seek innovative and cost-effective ways to reduce the demand for emergency inpatient care and increase the efficiency of such care. 


\section{Conclusion}

The main aim of this study was to improve understanding of the rise in emergency hospital admissions of older people in England to inform policy development and funding decisions.

The analysis showed that the emergency admission rate for older people rose by $2.1 \%$ per year over the period $2001 / 02$ to $2012 / 13$ but the bed day rate fell by $2.0 \%$ per year. The rate rose especially rapidly for the oldest age group (85 and over), for people with flu/pneumonia or urinary tract infection, for short hospital stays, and for stays involving procedures.

An analysis of age, period and cohort effects found that: admission rates rise monotonically with age from age 40 upward; each cohort from those born in around 1924 onward experienced lower emergency admission rates after standardising for age and period effects; and period effects have been increasing over the period since 2001/02. This coincided with rising health expenditure to 2010 and may reflect resulting investment and adoption of new technologies. The critical cohort and period effects are similar for men and women, while the positive influence of age on emergency admissions begins at 30 for men and 45 for women.

Some suggestions arise from these findings which may be of international interest. First, other developed countries may 
also be experiencing a downward cohort effect for emergency admissions. This would not be surprising given evidence from various countries of rising healthy life expectancy [23] and of considerable concentration of health care expenditure in the final year(s) of life [24]. Secondly, the uptake of new technologies suggests that other countries may also be experiencing an upward period effect. This seems especially likely if the development of technologies, as well as economic growth prior to the financial crisis, is driving rising expectations. Third, falling lengths of stay, which are not unique to England, can allow bed days to fall even as admissions rise and populations age.

Population ageing is regularly given as a reason for increased demand for care and expenditure in the NHS, but these results suggest that supply side factors such as the adoption of new technologies are more likely to be the leading cause.

\section{Funding}

This work was supported by the Department of Health (core funding rather than numbered grant). The funder had no involvement in study design; in the collection, analysis and interpretation of data; in the writing of the report; and in the decision to submit the article for publication. 


\section{Conflict of interest}

The authors do not have any conflict of interest. (Although all of them have in the past worked at the Department of Health, none of them still work there).

\section{Acknowledgements}

The Centre for Health Service Economics and

Organisation wishes to thank the Department of Health in England for research funding, and a group of experts who provided advice at a workshop held in December 2013. A number of community geriatricians kindly responded to a survey. We are grateful for advice from Maria Aragon, Matthew Cooke, Daniel Lasserson, Jackie Morris, Catia Nicodemo, Stuart Redding and Louella Vaughan. Responsibility for the article rests with the authors alone.

\section{Appendix A}

Supplementary data Supplementary data associated with this article can be found, in the online version, at http://dx.doi.org/10.1016/j.healthpol.2017.05.007. 


\section{Endnotes}

[1]. Department of Health (2016) The Government's mandate to NHS England for 2016-17.

https://WwW.gov.uk/government/uploads/system/uploads/attachmen t_data/file/494485/NHSE_mandate_16-17_22_Jan.pdf, accessed 7 September 2016

[2]. Department of Health, Shared delivery plan: 2015 to 2020. https://WwW.gov.uk/government/publications/department - of health-shared-delivery-plan-2015-to-2020/shared-delivery-plan2015-to-2020. Accessed August 2016.

[3]. Department of Health, Shaping the Future NHS: long term planning for hospital and related services. Consultation document on the findings of the National Beds Inquiry, London: Department of Health, 2000

[4]. Blunt I, Bardsley M, Dixon J. Trends in emergency admissions in England 2004-2009: is greater efficiency breeding inefficiency? Nuffield Trust; 2010.

[5]. Schuur JD, Venkatesh AK. The growing role of emergency departments in hospital admissions. New England Journal of Medicine. 2012 Aug 2;367(5):391-3.

[6]. Jones R. Trends in emergency admissions. $\mathrm{Br} \mathrm{J}$ Healthc Manag. 2009 Apr;15(4):188-96. 
[7] Jones R. Is the demographic shift the real problem?.

British Journal of Healthcare Management. 2013 Oct;19(10):50911.

[8]. Smith P, Mckeon A, Blunt I, Edwards N. NHS hospitals under pressure: trends in acute activity up to 2022. London: Nuffield Trust. 2014 0ct.

[9]. Cowling TE, Soljak MA, Bell D, Majeed A. Emergency hospital admissions via accident and emergency departments in England: time trend, conceptual framework and policy implications. Journal of the Royal Society of Medicine. 2014 Nov;107(11): 432-8.

[10]. Payment by Results Guidance for 2010-11. http://webarchive.nationalarchives.gov.uk/20130107105354/http: //www.dh.gov.uk/prod_consum_dh/groups/dh_digitalassets/@dh/@en /@ps/documents/digitalasset/dh_112970.pdf accessed August 2016 .

[11]. Urgent and Emergency Care Review. Transforming urgent and emergency care services in England. London: NHS England. 2015

[12]. House of Commons Health Committee. Urgent and emergency care: second report of session 2013-14, HC171. London: House of Commons. July 2013 
[13]. Office for National Statistics. Mid-year population estimates.https://WWW. ons.gov.uk/peoplepopulationandcommunity/ populationandmigration/populationestimates/bulletins/annualmid yearpopulationestimates

[14]. See http://www.hscic.gov.uk/hes

[15]. Wittenberg R, Sharpin L, McCormick B, Hurst J. Understanding emergency hospital admission of older people. 0xford: Centre for Health Service Economics and Organisation. 2014

[16]. Yang $Y$, Land KC. Age-period-cohort analysis: New models, methods, and empirical applications. CRC Press; 2013 Feb 25.

[17]. Yang Y, Schulhofer-Wohl S, Fu WJ, Land KC. The Intrinsic Estimator for Age-Period-Cohort Analysis: What It Is and How to Use It. American Journal of Sociology. 2008 May;113(6):1697736.

[18]. Patients who are admitted as emergencies and discharged on the same day are counted among admissions in England. [19]. Wittenberg R, Redding S, Nicodemo C, McCormick B. Analysis of trends in emergency and elective hospital admissions and hospital bed days: 1997/98 to 2014/15. [20]. Office for National Statistics (ONS). Healthy life expectancy at birth and age 65 by upper tier local authority 
and area deprivation: England, 2012 to 2014. Newport: Office for National Statistics. 10 March 2016

[21]. Werblow A, Felder S, Zweifel P. Population ageing and health care expenditure: a school of 'red herrings'?. Health economics. 2007 oct 1;16(10):1109-26.

[22]. Howdon D, Rice N. Health care expenditures, age, proximity to death and morbidity: implications for an ageing population. 2015 Jan.

[23]. e.g. http://ec.europa.eu/eurostat/statistics-

explained/index.php/Healthy_life_years_statistics. Accessed August 2016 .

[24]. Staiger, U., and Chaytor S. 2016. The Future of Healthcare in Europe. London:

UCL.https://WWW.ucl.ac.uk/european-institute/eventsview/reviews/healthcare/FHE_FINAL_online.pdf. Accessed August 2016. 